7. Child Lang. 33 (2006), 303-320. (C) 2006 Cambridge University Press doi:I0.1017/So305000906007380 Printed in the United Kingdom

\title{
Learning to use demonstratives in conversation: what do language specific strategies in Turkish reveal ?*
}

\author{
A YLİN C. KÜNTAY \\ Koç University, Istanbul
}

AND

ASLI ÖZY ÜREK

Koç University, Istanbul and Max Planck Institute

for Psycholinguistics, Nijmegen

(Received I 5 October 2003. Revised I 2 August 2005)

\begin{abstract}
Pragmatic development requires the ability to use linguistic forms, along with non-verbal cues, to focus an interlocutor's attention on a referent during conversation. We investigate the development of this ability by examining how the use of demonstratives is learned in Turkish, where a three-way demonstrative system $(b u, s ̧ u, o)$ obligatorily encodes both distance contrasts (i.e. proximal and distal) and absence or presence of the addressee's visual attention on the referent. A comparison of the demonstrative use by Turkish children (6 four- and 6 six-year-olds) and 6 adults during conversation shows that adultlike use of attention directing demonstrative, $s u$, is not mastered even at the age of six, while the distance contrasts are learned earlier. This language specific development reveals that designing referential forms in consideration of recipient's attentional status during conversation is a pragmatic feat that takes more than six years to develop.
\end{abstract}

[*] This work has been supported by the Turkish Academy of Sciences, in the framework of the Young Scientist Award Program to Aylin C. Küntay (EA-TÜBA-GEBIP/200I2-I3) and Aslı Özyürek (HAÖ/TUBA-GEBIP/200ı-2-ı6). We would like to thank David Wilkins for his valuable comments on this paper. Pelin Kesebir, Sanem Günay, Şirin Duruk, İbrahim Şenay, and Engin Arrk helped in recording and transcribing the adult data, and coding the entire corpus. Tilbe Göksun, Carmel O'Shannessy, and Leah Roberts helped with final editorial changes. Author names appear in alphabetical order. Both authors contributed equally to the paper. Address for correspondence: Aylin C. Küntay, Ph.D., Koç University, Department of Psychology, Sariyer - 3445o, İstanbul, Turkey. tel: +902I2338 I4 09; fax: +902I23383760; e-mail: akuntay@ku.edu.tr 
I N T RODUCTION

In order to communicate effectively in conversation, participants must agree on what is being talked about and must be able to establish joint attention on conversationally relevant referents. Thus, during development children have to learn how to use linguistic forms, along with the use of appropriate non-verbal cues, to focus their interlocutors' attention on referents to ground further conversational exchanges (Clark, 2003).

One domain where acquiring this skill is especially prominent is in the exophoric use of demonstratives to refer to entities in the extralinguistic spatial context of the utterance. Because of their indexical nature, the exophoric use of demonstratives typically calls for coordinating their use with the knowledge about the constantly changing relative distance of the referred entities in relation to the interlocutors as well as the attention of the addressee(s) on the referents. Thus, how children learn to use demonstratives exophorically provides a good window into pragmatic development, and specifically how children learn to use linguistic forms to focus an interlocutor's attention on a referent during conversation.

The present study addresses this question by investigating how Turkish children learn to use a three-way demonstrative system in which the choice of demonstrative pronouns (henceforth, DPs) requires the speaker to monitor and assess whether or not the addressee's visual attention is already on the referent. The Turkish demonstrative system encodes not only distance contrasts (i.e. proximal $(b u)$ versus distal $(o)$ ), but also the absence of the addressee's visual attention on the referents (şu) (Özyürek, r 998 ; Özyürek \& Kita, 2000). For example, imagine a dinner with two people, where one of them needs to refer to a glass away from her on the table. In English the speaker could say 'could you pass me that glass?' since the glass is away from where she is sitting. However, in Turkish, depending on the addressee's visual attention on the referent, the speaker would use şu if the addressee's visual attention is away from the glass (e.g. when she is concentrated on the food), but use $o$, that is the distal form, if the addressee's attention is directed towards or presumed to be on the referent. Thus, the strategies through which Turkish children master the adult demonstrative system in conversations can be revealing both about children's ability to learn a specific demonstrative system and about pragmatic development in general.

\section{Adult use of demonstratives}

Demonstratives are those expressions that serve to direct the hearer's attention towards a referent by encoding different spatial and temporal aspects of the situation that delimit the search space within which the referent is located. For example, the word 'this' in the phrase 'Look at this!!!' is interpretable only by figuring out the spatial aspects of the 
situation such as who the speaker is and the relative distance of the referent in relation to the speaker among other aspects.

Previous research has shown that demonstrative terms in many languages encode relative distance contrasts concerning the relation of the referent to the speaker and/or the addressee (e.g. here for proximal and there for distal or non-proximal) (e.g. Anderson \& Keenan, I 985 ; Fillmore, I997; Kemmerer, I 999). Recent literature on crosslinguistic analysis of demonstrative systems has shown that, in many languages, demonstratives also encode additional contrasts such as the visibility of objects or the addressee's attention status with respect to the referents (e.g. Hanks, I990; Özyürek \& Kita, 2000; Burenhult, 2003). For example, the addressee's prior visual and/or cognitive attention/knowledge state regarding a referent have been found to influence the speaker's choice of certain demonstratives over others in different languages regardless of distance parameters (e.g. the choice of şu over $b u$ or $o$ in Turkish (Özyürek, I 998), or tun over ton in Jahai (Burenhult, 2003) in the absence of the addressee's visual attention on the referent).

\section{Development of the use of demonstratives}

These findings suggest that, in many languages of the world, children have to learn various contrasts (e.g. relative distance, visual attention, location) encoded by the adult demonstrative system, which requires a tight coordination between the use of DPs and the changing parameters of the face-to-face context.

Most of the previous research on the development of demonstratives has focused on how children learn distance contrasts in their production and comprehension of demonstratives (Clark \& Sengul, I978; Tanz, I980; Wales, I986). These studies have focused mostly on English and have shown that, in spite of the complex parameters that are needed to master their correct use, demonstratives are used in very early speech. Terms like here, there, this, and that are usually present by age two and a half, appearing early and frequently in one- and two-word utterances in various languages (see Clark \& Sengul I978, for a summary).

Yet, the experimental studies on the comprehension of these forms (Clark \& Sengul, I978; Tanz, I980) show that children, in their early uses of deictic terms, do not encode any distance contrasts and the adultlike use of these terms is not achieved before six or seven years of age. Similarly, Hallan (200I), in providing an analysis of over here/over there in an adultchild interaction corpus proposes that the first uses of demonstratives in naturalistic interactions do not encode distance distinctions. Instead, it is argued that in their early uses, along with handling of objects, demonstratives function prominently as 'attention getters' (Wales, I986), and that distance distinctions are learned later. 
With regard to the ability to use demonstratives with nonverbal means, research on early uses has shown that children first use pointing gestures around the end of the first year (e.g. Bates, Camaioni \& Volterra, I975) to focus the participant's attention on objects. Pointing plus deictic word combinations emerge around the age of 20 months (Capirci, Iverson, Pizzuto \& Volterra, I 996) and the ability to use deictic words alone begins after 2 I months (Rodrigo, Gonzalez, de Vega, Muneton \& Rodriguez, 2004). After this stage, it is reported that children continue use both pointing and deictic terms throughout development (Rodrigo et al., 2004; see also Clark \& Sengul, 1978 for a similar stage of development from pointing to emergence of deictic words), even though not much research is done on later years of childhood.

This previous literature on the acquisition of deictic forms has some limitations. First of all, there is little research on how children learn demonstrative systems in languages that encode contrasts other than distance such as attentional status of addressees regarding referents. Secondly, they do not give information about how children dynamically use demonstratives as contrastive linguistic devices for coordinating attention with conversational participants. Even though demonstratives might be employed early on for getting attention (Clark \& Sengul, i 978), in line with their emergence along with pointing gestures and handling objects (Capirci, Iverson, Pizzuto \& Volterra, I996; Wales, I986), this is only part of the story. The ability to monitor the addressee' visual attention so that demonstratives can be used to differentially manipulate the participants' attentional states in conversation might develop much later. In other words, a skill such as achievement of mutual attention may appear at different levels of complexity (simple attention getting vs. dynamic attention manipulation), and at different points in development (early vs. late preschool age). In addition, the availability of skills such as gestural and verbal behavior early on does not necessarily mean that young children can integrate these components to function at the level of adultlike complexity in regulating the attentional states of their interactants during conversational interactions. Therefore, how children learn to use demonstrative forms as contrastive linguistic devices in order to dynamically monitor and manipulate attentional states of others and how this skill develops, in addition to encoding distance constrasts, remain open questions.

\section{Present study}

In this paper we investigate how children learn to use demonstrative pronouns in Turkish, where DPs (i.e. $b u, s\}, o$ ) obligatorily and systematically encode distance contrasts as well as the presence or the absence of the addresee's visual attention on the referent (Özyürek, I998; 
Özyürek \& Kita, 2000). Turkish makes a three-way distinction in its demonstrative system: $b u, s ̧ u$, and $o$. These pronouns take all the case markings (e.g. accusative $-i$, dative $-a$ ) and the same forms can be used as adnominals as well ( $b u$ kitap 'this book'). Demonstrative locatives, such as adverbials of place (burda, şurda, orda 'here/there'), are derived from the pronouns by adding a locative suffix $(-d a)$.

In the linguistics literature, there have been contradictory claims with regard to how the semantics of the Turkish three-way distinction can be described. Some researchers (Kornfilt, I 997) have proposed a speaker-based system where $b u$ is used for objects proximal to speaker, şu for medial proximity, and $o$ for objects distal to the speaker. However, Lyons ( I 977) has proposed a speaker and addressee anchored distance system where $b u$ refers to objects proximal to the speaker, ş $u$ proximal to the addressee, and $o$ distal to both the speaker and the addressee. Finally, in some accounts $s ̧ u$ has been considered as a variant of $b u$, that is, also encoding proximity but with an additional emphatic function (Underhill, I976).

In challenging these past accounts of the Turkish demonstrative system, Özyürek (I998) and Özyürek \& Kita (2000) have provided an analysis of the Turkish demonstrative system based on investigations of videotaped spontaneous conversational data. In these analyses, it is shown that the usage of $s ̧ u$ in naturalistic conversation cannot be explained by any of the distance-based accounts proposed so far. That is, şu does not encode distance of the spatial location of the referents in relation to any of the participants and is neutral with regard to distance specifications. Rather, the choice of the demonstrative şu is determined with regard to whether the addressee's visual attention has been on the object referred to or not before use of the demonstrative form by the speaker. Previous research has shown that if the addressee's eye gaze is not on the referent, speakers are more likely to use şu instead of $b u$ or $o$ regardless of the distance of the referent. On the other hand, $b u$ or $o$ are typically used when the visual attention of the addressee is already established or presumed to be on the referent. The latter two demonstrative forms do encode distance contrasts, as also shown by the previous analyses of Turkish (e.g. Underhill, ı976; Kornfilt, I 997). That is, $b u$ is used for proximal and $o$ for distal referents.

In sum, the Turkish DP system can be explained by the following account. Turkish encodes two types of contrasts in its demonstrative system: (a) addressee's visual attention status in relation to the referent (i.e. presence or absence) and (b) the distance of the referent in relation to the speaker (i.e. proximal versus distal). Table I provides a summary of the Turkish demonstrative system.

In the present study, we analyse how Turkish adults and children use different DPs in conversations. In line with the proposed analysis, we expect adults to use $b u$ and $o$ differentially for encoding the distance of 
TABLE I. Analysis of the Turkish demonstrative pronoun system (Özyürek, I998; Özyürek छ Kita, 2000)

\begin{tabular}{lcc}
\hline & \multicolumn{2}{c}{ Distance of the referent } \\
\cline { 2 - 3 } $\begin{array}{l}\text { Addressee's visual } \\
\text { attention on the referent }\end{array}$ & $\begin{array}{l}\text { Proximal to } \\
\text { the speaker }\end{array}$ & $\begin{array}{c}\text { Distal to } \\
\text { the speaker }\end{array}$ \\
\hline $\begin{array}{l}\text { Present/Neutral* } \\
\text { Absent }\end{array}$ & $b u$ & $s u$ \\
\hline$s u$ & $s u$ \\
\hline
\end{tabular}

Note: This category includes cases where the speaker presumes addressee's attention to be on the referent or is neutral with regard to its presence or absence.

referents in relation to the speaker: $b u$ will be used most frequently for objects proximal and $o$ for objects distal in relation to the speaker. However, we do not expect şu to be used differentially in terms of distance contrasts but in terms of addressee's visual attention. In particular, we expect the use of şu to be coordinated tightly with the visual attention of the addressee on the referent, being used primarily when the addressee's visual attention is not on the referent.

For children, we expect DPs that encode distance contrasts to be learned earlier than şu, since their use does not require tight coordination of verbal devices with the monitoring and manipulation of the visual attentional states of others in conversation. On the other hand, we expect the adultlike patterns in the use of şu to develop late in children compared to $b u$ and $o$. Şu might be used less frequently, and when used, it might not be coordinated with appropriate nonverbal parameters such as addressee's visual attention in the ways employed by adults.

These predictions about the late acquisition of the attention-encoding demonstrative are based on other research regarding children's late developing ability to use appropriate linguistic means to manipulate the attentional states of others. Taking a listener's perspective and adjusting a linguistic form accordingly is an ability that develops after preschool years (Pan \& Snow, 1999). Children, learning to speak various languages, do not appropriately preface nouns that are not accessible to their listeners' vision and knowledge with indefinite forms until about age 7 (Karmiloff-Smith, I 979; Hickmann, Hendriks, Roland \& Liang, I996; Küntay, 2002). Thus, even though demonstrative pronouns in early speech might be employed for getting attention (Clark \& Sengul, I978; Wales, I986), the ability to monitor and manipulate the participants' attentional states with the differential choice of demonstratives in conversation might develop much later. As a consequence, we expect later development of the appropriate use of $s u$ compared to $b u$ and $o$ in Turkish children's conversations. 
In order to investigate these questions, we analyse the use of Turkish DPs in task-related conversational data from two age groups of children (four-year-olds and six-year-olds) and adults as they are constructing a lego model. This type of task naturally elicits many demonstrative forms, leading to reference to objects in varying distances and to shifting visual attentional states of the participants with regard to these objects.

The conversational data are videotaped and analysed for verbal and nonverbal parameters that are relevant for the use of demonstratives, such as the distance of the referents in relation to the speaker and the eye gaze of the addressee on the referent as an index of visual attention. These are the measures (i.e. distance and eye gaze patterns) which will reveal whether children use demonstratives for similar contrasts as the pattern of contrasts displayed by adults.

\section{METHOD}

\section{Participants}

Participants are 6 college-age adults, 6 six-year-olds (mean age $=5 ; 9$; range $=5 ; 6-6 ; \mathrm{I}$ ) and 6 four-year-olds (mean age $=4 ; \mathrm{I}$, range $=3 ; \mathrm{I} 0-4 ; 5$ ), who participated as three pairs of conversational partners in each age group. All pairs were composed of individuals who reported to be 'friends'. The data were collected in preschools for children and on a college campus for adults in Istanbul, Turkey. All participants are monolingual Turkish speakers.

\section{Procedure}

Participants were given a picture of a model made of lego pieces of different shapes and colors, and asked to reconstruct this model collaboratively with actual lego pieces. The setup in this study is a joint activity that calls for close coordination between pairs. This allows elicitation of demonstrative data in a naturalistic setting and presents a good way of collecting fairly dense data compared to what one might get in unstructured conversations.

Each pair was videotaped for 12 minutes. Later all the utterances in the videos were transcribed and relevant nonverbal acts were coded.

\section{Coding}

The transcripts were first segmented into utterances. Later, for all the utterances that contained DPs, the following verbal and spatial features were coded from the transcripts and the videos:

( I) Type of DP: which one of the DPs is used in the utterance (i.e. $b u$, şu, or $o$ ). Here we considered DPs in all morphological contexts they 
were used in (i.e. locative, $-d a$, dative $-a$, accusative $-i$ ) and also when they were used as adnominals (bu kitap 'this book').

(2) Referent object's relative distance: whether the object referred to by the $\mathrm{DP}$ is near the speaker or away from the speaker. The latter includes space near the addressee, in between the speaker and the addressee, and away from both of the participants.

(3) Addressee's eye-gaze on the referent before the use of the DP by the speaker: whether the addressee's eyegaze was on the object referred to prior to the use of the DP by the speaker or not.

The data were coded by two undergraduate psychology students who were trained by the authors about the coding categories. Both were blind to the motivations and expectations of the study. To examine intercoder agreement, a third coder coded $25 \%$ of the utterances where DPs were used with respect to the referent's relative distance and addressee's eyegaze on the referent. The interrater agreement is $86 \%$ for relative distance of the referent from the speaker (Cohen's kappa $=0.7 \mathrm{I}$ ), and $89 \%$ for addressee's eyegaze on the referent (Cohen's kappa $=0 \cdot 74$ ).

\section{ANALYSIS AND RESULTS}

The results are presented as a series of analyses that investigate two aspects of the use of the DPs: (a) their distributional patterns in each age group, and (b) how they are used in relation to different spatial features of the conversational interaction (i.e. distance of referents and addressee's eyegaze patterns). First, we present findings about adult use of demonstratives, and later we compare six- and four-year-olds' patterns in relation to those of the adults.

\section{Analysis I : Adult use of DPs}

The analysis of the adults' use of DPs is presented first to set a baseline in relation to which children's use of demonstratives can be compared.

Distribution of the use of DPs. The first analysis investigated the frequency and distribution of the DPs in adult conversations. The results showed that $38 \%$ of the utterances $(N=739)$ contained at least one DP. Further analysis revealed that the distribution of the three types of demonstratives differed from each other $\left(\chi^{2}(2, N=28 \mathrm{I})=25.99, p<0.00 \mathrm{I}\right)$ in a total of $28 \mathrm{I}$ DPs. While the mean percentages of the usage of $b u$ $(37 \%)$ and $s ̧ u(4 \mathrm{I} \%)$ were very similar, the percentages of the use of both bu $\left(\chi^{2}(\mathrm{I}, N=\mathrm{I} 58)=\mathrm{I} 3.98, p<0.00 \mathrm{I}\right)$ and $s u\left(\chi^{2}(\mathrm{I}, N=\mathrm{I} 78)=25.22\right.$, $p<0.00 \mathrm{I})$ were higher than the use of $o(22 \%)$. This could be attributed to the fact that in the lego construction task, there were few referents away 


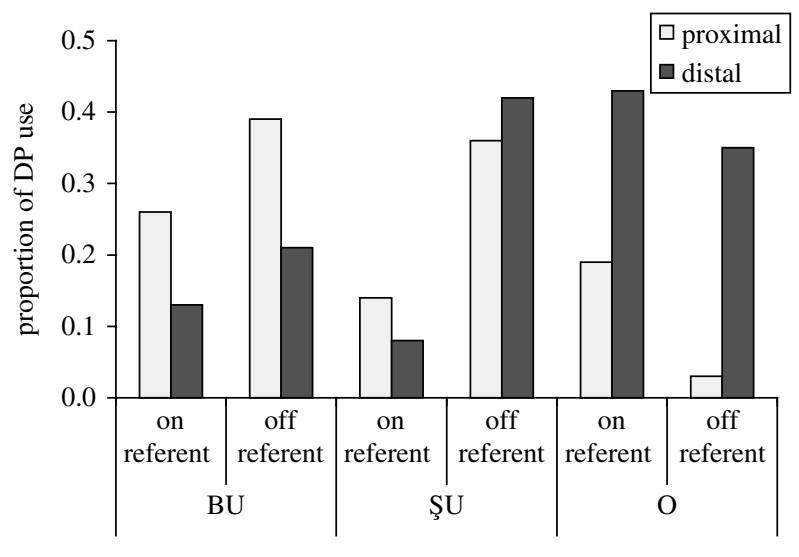

Addressee's visual attention and type of DP

Fig. I. Mean proportions of the adult use of each DP with regard to relative distance of the referent and the addressee's visual attention on the referent.

from the participants that would have required the use of $o$. Thus, the participants mostly used either $b u$ or şu to refer to the objects.

The second part of the analysis investigated whether the three DPs were used differentially with regard to the two variables of distance of the referents and addresee's visual attention.

Use of DPs in relation to distance of the referent and the addressee's visual attention. According to the account of the Turkish demonstrative system proposed by Özyürek ( I 998) and Özyürek \& Kita (2000), we expected $b u$ to be mostly used for objects proximal to speaker, $o$ for distal to speaker, but we did not expect them to be used contrastively for addressee's visual attention. However, we expected şu to be used contrastively in relation to addressee's visual attention, but not for distance of the referents in relation to the speaker.

Proportions of the use of each demonstrative per subject with regard to distance of the referent from the speaker (proximal or distal) and the addresee's visual attention (on the referent or not) were calculated. Figure I shows the use of each demonstrative type in relation to these parameters.

Three (2) $\times(2)$ repeated measures ANOVAs with distance (proximal or distal) and the addresee's visual attention (on the referent or not) as independent variables were conducted on the mean proportions of the use of $b u$, şu and $o$ separately.

The analyses on the mean proportions of the demonstrative $b u$ revealed only a main effect of distance of the referent $(F(\mathrm{I}, 5)=6.80 ; p<0.05)$, but not a main effect of the status of addressee's visual attention, or an 
interaction between the two factors. As expected, speakers used $b u$ more frequently when the referent was proximal $(M=0.33)$ than when it was distal to the speaker $(M=0 \cdot 17)$.

On the other hand, the same analysis conducted for şu revealed only a main effect of addresee's visual attention $(F(\mathrm{I}, 5)=7 \cdot 77 ; p<0 \cdot 05)$, but not a main effect of the distance of the referent, or an interaction between the two variables. Şu was used more frequently when the addressee's attention was away from $(M=0 \cdot 39)$ rather than on the referent $(M=0 \cdot$ I I $)$.

The final ANOVA conducted on the mean proportions of the use of $o$ revealed main effects of both distance of the referent $(F(\mathrm{I}, 5)=\mathrm{I} 2 \cdot 04$; $p<0.05)$ and the visual attention of the addressee $(F(\mathrm{I}, 5)=9.56, p<0.05)$, but no interaction between the two variables. Speakers used $o$ more frequently when the referent was distal $(M=0.39)$ rather than proximal to the speaker $(M=0 \cdot \mathrm{II})$. Secondly, $o$ was used more often when the addressee's attention was on the referent $(M=0.3 \mathrm{I})$ rather than away from it $(M=0 \cdot 18)$.

These findings confirm the predictions, in that, $b u$ was mostly preferred when referents were proximal to the speaker and $o$ for those that were distal. On the other hand, the use of $s ̧ u$ was not found to be sensitive to the distance of the referents, but rather to the addressee's visual attention. Şu was more likely to be used when the addressee's visual attention was away from rather than when it was on the referent. Finally, the use of $o$ was also found to be sensitive to the addressee's visual attention. However unlike the use of şu, o was more likely to be used when the addressee's visual attention was on the referent. This is in line with the proposed analysis (as in Table I) of the Turkish demonstratives, in that the uses of $b u$ and $o$ mainly encode distance contrasts and the addressee's visual attention is either presumed to be on the referent (i.e. in the use of $o$ ) or not taken into consideration (i.e. in the use of $b u$ ).

\section{Analysis 2: Children's use of DPs}

How do Turkish chidren learn to use such a split DP system where both attentional and distance contrasts are encoded? The analyses below compare the frequency and distribution of the DPs as well as their use in relation to spatial features of the context between adults and children.

Developmental distribution of the use of the DPs. The results showed that both four- and six-year-olds used fewer DPs per utterance than adults. That is, I9\% of all utterances by four-year-olds $(N=782)$ and $20 \%$ of the utterances by six-year-olds $(N=970)$ contained at least one DP, whereas for adults this percentage was $38 \%$.

Secondly, the distribution of the three DPs was compared across the two groups of children and adults (Figure 2). 


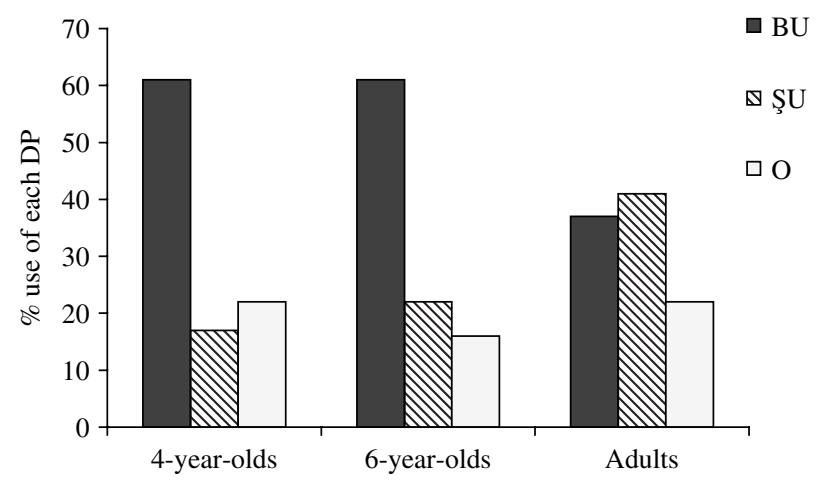

Fig. 2. Distribution of the different types of DPs in total DP usage across ages.

No difference was found between the six-year-olds and four-year-olds. However, the distribution of DPs differed in children as a group from those of adults $\left(\chi^{2}(2, N=637)=52.64, p<0.001\right)$. In children's conversations (both groups combined), the mean percentages of the use of şu $(20 \%)$ and $o$ ( $8 \%$ ) were very similar, while the percent use of $b u(62 \%)$ was higher than both the use of $s\}\left(\chi^{2}(\mathrm{I}, N=284)=80.28, p<0.00 \mathrm{I}\right)$ and $o\left(\chi^{2}(\mathrm{I}\right.$, $N=280)=85.80, p<0.00$ I). However, for adults, we had found that the uses of $b u$ and şu were very similar and higher than the use of $o$.

The next analysis aimed to determine how children used DPs with regard to distance of referents and the addressee's visual attention on the referent. Such an analysis would reveal whether preschoolers encoded the distance and the visual attentional contrasts in the way that adults did in their use of DPs.

Development of the use of the DPs in relation to distance of the referents and the addressee's visual attention. In order to determine whether children in the two age groups used similar contrasts with $b u$, şu and $o$ as adults did, we first calculated the mean proportion of the use of each DP for each child with regard to distance of the referent and the addressee's visual attention on the referent. The mean proportions for each demonstrative were compared with those of adults in a $(3) \times(2) \times(2)$ repeated ANOVA with age (four-year-olds, six-year-olds, and adults) as a between subject variable and distance (proximal and distal) and the addresee's visual attention (on the referent or not) as within subject variables. Figures $3 a, 3 b$, and $3 \mathrm{c}$ below show the mean proportions for each demonstrative with regard to distance of the referent and the addressee's visual attention status for each age group.

The first ANOVA conducted on the mean proportions of $b u$ revealed only main effect of distance of the referent $(F($ I, I 4$)=19.94 ; p<0.00$ I $)$, but 


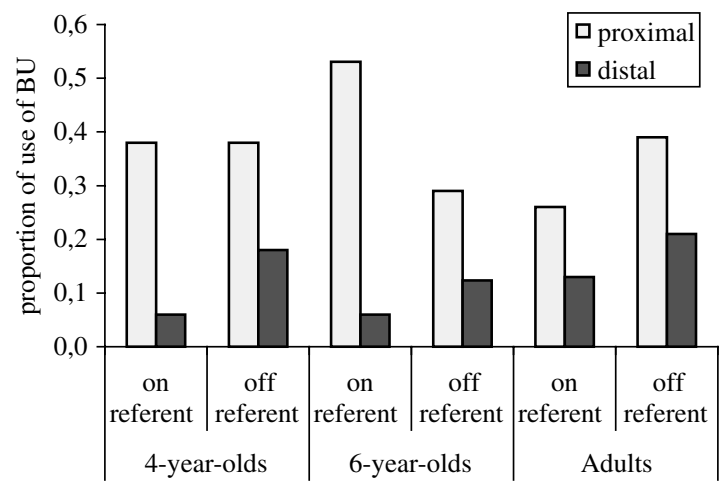

(a) addressee's visual attention and age groups

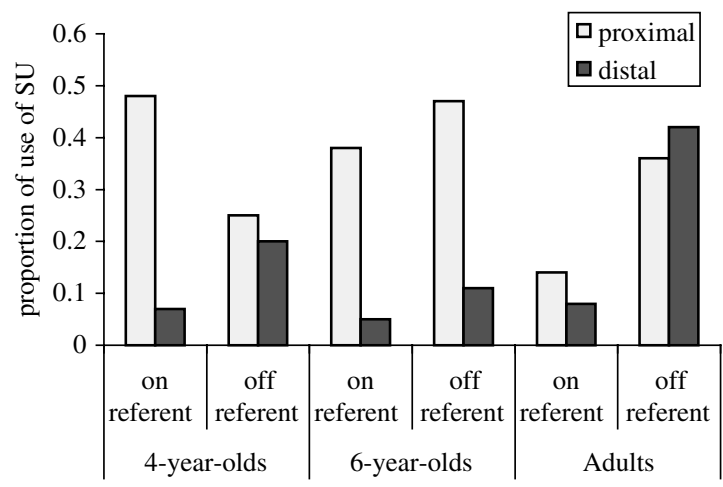

(b) addressee's visual attention and age groups

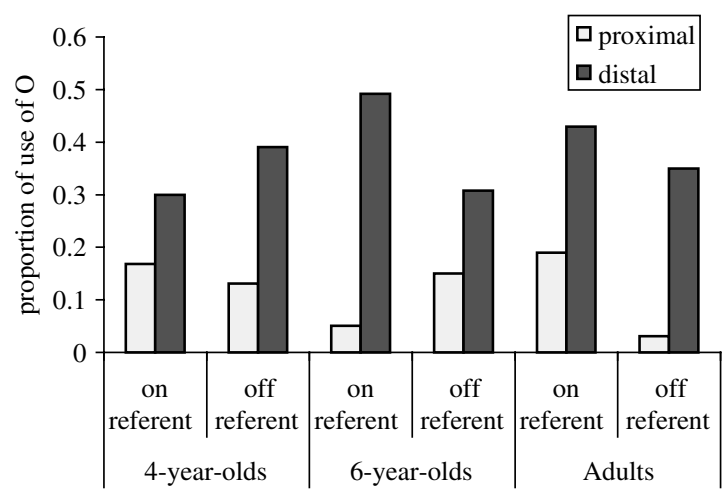

(c) addressee's visual attention and age groups

Fig. 3. (a,b,c) Mean proportions of the use of each DP with regard to distance and the addressee's visual attention across ages. 
no effects of age, addressee's visual attention, or interaction between any of the variables. That is, both children and adults were more likely to use $b u$ for referents proximal to rather than distal from the speaker.

The next ANOVA was conducted on the mean proportions of şu. This analysis revealed main effects of the distance of the referent $(F(\mathrm{I}, \mathrm{I} 2)=5 \cdot 20$, $p<0.05)$, of visual attention $(F(\mathrm{I}, \mathrm{I} 2)=\mathrm{I} \mathrm{I} \cdot 6 \mathrm{I} ; p<0.0 \mathrm{I})$, and a marginal effect of interaction among the the age, distance, and visual attention variables $(F(\mathrm{I}, \mathrm{I} 2)=3.08, p=0.08)$. Due to the marginal interaction effect, two separate $(2) \times(2)$ repeated measures ANOVAs were conducted, one for four-year-olds and one for six-year-olds, with distance and the addressee's visual attention as within subject variables. In the six-year-olds' analysis, the ANOVA revealed a main effect of addressee's visual attention $(F(\mathrm{I}, 4)=5.80 ; p<0.05)$, a marginally significant effect of the distance of the referent $(F(\mathrm{I}, 4))=2 \mathrm{I} \cdot 34, p=0.07)$, and a marginal interaction between the two variables $(F(\mathrm{I}, 4)=5.68 ; p=0.08)$. The second ANOVA conducted for the four-year-olds did not reveal any main effects or interaction between any of the variables, even though the mean proportions of şu usage were larger for referents proximal $(M=0.33)$ than those distal to the speaker $(M=0 \cdot \mathrm{I} 6)$.

These results reveal that child groups use the demonstrative şu in different ways than adults, who encode mainly attentional contrasts with this demonstrative. Six-year-olds take both distance and addressee's visual attention into consideration in their use of $s u$. They are most likely to use $s u$ when the referent is both proximal and the addressee's attention is away from the referent as indicated by the marginal interaction. On the other hand, even though the effect is not significant, four-year-olds seem to be taking only the distance of the referent into consideration in their use of şu.

Finally, a repeated $(3) \times(2) \times(2)$ ANOVA conducted on the main proportions of $o$ revealed only a main effect of distance $(F(\mathrm{I}, \mathrm{I} 2)=2 \mathrm{I} \cdot \mathrm{I} O$, $p<0.00 \mathrm{I}$ ), but not any other main effects or interactions. This analysis also showed that all groups used $o$ more frequently when the referent was distal rather than proximal to the speaker. However, there is no evidence that children took addressee's visual attention into consideration when using the demonstrative $o$ as adults did.

\section{CONCLUSION AND DISCUSSION}

In this study, we examined Turkish children's (four- and six-year-olds) developing ability to use DPs in conversational context. Turkish offers a special challenge in learning how to use demonstratives exophorically for children, given that it encodes both distance and attentional contrasts in its three-way demonstrative system. The results in general show that 
Turkish-speaking preschool children demonstrate adultlike competence in their production of $b u$ and $o$ as reflected in the frequency of the use of these DPs as well as in their function in terms of marking distance contrasts. However, they use the attention encoding DP, şu, much less than adults. Furthermore, when they do so, they can not yet mark the attentional contrasts at adult levels and initially use it to refer to proximal referents. Below we summarize the overall findings, and then discuss their implications for a general understanding about learning to use demonstrative forms specifically and about pragmatic development in general.

One of the main findings of the study is that in a collaborative task with distributed objects, adults use more demonstratives per utterance than children. The relative frequeny of the use of DPs in adult conversations is contrary to findings for picture-based narrative discourse, where several researchers found that young children prefer to encode objects through deictic devices rather than explaining the contents of the pictures through verbally explicit means (Berman \& Slobin, I994). Our findings show that in the kinds of tasks where deictic reference is needed for successful collaboration and mutual orientation to referents as in conversations, adults do use more demonstratives than children. This indicates that deictics are not necessarily developmentally less mature devices than more elaborate means of referring. Furthermore, this could be a language specific finding due to the fact that Turkish adults' relative mastery of the use of şu compared to children might have increased their use of DPs in general in this collaborative task.

With respect to distributional patterns of demonstrative forms, differences between children's and adults' data are especially apparent with the use of $s\}$, a form used for conversational management of mutual attention by adults. Adults use şu most frequently, followed closely by $b u$. Unlike adults, children predominantly prefer $b u$ over şu. The percentage of the use of $o$ does not differ in children's and adults' talk. Children seem to default to the employment of $b u$ where şu would be used according to the patterns observed in adult conversations, suggesting they have not yet entirely figured out the contexts where şu should be used.

The use of demonstratives in adults confirms the findings of Özyürek (r 998) and Özyürek \& Kita (2000) in that adults tend to use şu as a distanceneutral form for all the locations coded in this study, while $b u$ is preferred for objects proximal and $o$ for objects distal to the speaker. In addition, we found the use of $o$ also to be sensitive to addressee's visual attention. However, in contrast to the use of $s u$, $o$ is used more frequently in the presence of attention.

Children show similarities to as well as differences from adults in their consideration of speaker-based distance parameters and manipulating the addressee's visual attention when using DPs. Children's use of DPs with 
TABLE 2. Encoding of spatial parameters in children's versus adults' use of the Turkish demonstratives

\begin{tabular}{|c|c|c|c|c|c|c|}
\hline \multirow[b]{2}{*}{$\mathrm{DP}$} & \multicolumn{2}{|c|}{ Four-year olds } & \multicolumn{2}{|c|}{ Six-year olds } & \multicolumn{2}{|c|}{ Adults } \\
\hline & Distance & $\begin{array}{c}\text { Visual } \\
\text { Attention }\end{array}$ & Distance & $\begin{array}{c}\text { Visual } \\
\text { Attention }\end{array}$ & Distance & $\begin{array}{c}\text { Visual } \\
\text { Attention }\end{array}$ \\
\hline $\mathrm{BU}$ & Proximal & Neutral & Proximal & Neutral & Proximal & Neutral \\
\hline $\mathrm{SU}$ & Proximal & Neutral & Proximal & Absent & Neutral & Absent \\
\hline $\mathrm{O}$ & Distal & Neutral & Distal & Neutral & Distal & Present \\
\hline
\end{tabular}

respect to distance is not that different from that of adults. The basic distinction of preferring $b u$ for objects proximal and $o$ for objects distal to the speaker is already acquired by children of age four. This is a purely speaker-based assessment. However, encoding of addressee's visual attentional with the use of şu develops much later; it is not existent in four-year-olds, and partially available for six-year-olds with an additional distance encoding function. Thus, four-year-olds and six-year-olds, to a large extent, seem to use şu taking into account distance-based contrasts, that is, to refer to objects proximal rather than distal to the speaker, rather than based on attention-related contrasts. The relatively late development of encoding of attentional contrasts is also evident in the finding that none of the child groups used the additional attention function of $o$ that adults employ. Table 2 summarizes our understanding of how children versus adults use the Turkish three-way demonstrative system.

\section{General remarks}

Why do Turkish children learn to use şu which encodes attentional contrasts later than $b u$ and $o$ which encode mainly distance contrasts? More importantly, what does this tell us about pragmatic development in general ?

One reason for the late mastery of the use of şu could be that the use of this demonstrative needs the mastery of coordinating a linguistic form differentially with the visual attention of the addressee in a dynamic conversational interaction. Given previous research indicating children's early development of joint attention skills (e.g. Tomasello \& Haberl, 2003), we would have expected four-and especially six-year-old children to have mapped şu onto its function quite early in a linguistic system that encodes joint attention as a basic contrast. However, we have not found this to be the case. One of the reasons for this is that here we are not tapping into basic joint attentional capacities, but to the deployment of specific linguistic forms during conversational management of attention. 
The late development of the same capacity is also tapped in the extensive literature on children's usage of indefinite vs. definite linguistic forms in introducing and maintaining referents in extended discourse (e.g. Karmiloff-Smith, I 979; Bavin, I987; Wigglesworth, I990; Clancy, I 992; Nakamura, I 993; Dasinger, I995; Hickmann et al., I 996 ; Küntay, 2002). One finding in this literature consistent with our findings is that the usage of language-specific devices for expressing indefiniteness is not established before six or seven years of age, approaching adult patterns only by about ten years of age. These devices are employed for marking referents that are brought to the attention of the addressee for the first time. In this respect they are similar to the demonstrative pronoun şu in its function of calling for the addressee to direct his/her attention so that both the speaker and the addressee can share joint attention on a referent. Although demonstrative pronouns are among the earliest lexical forms to emerge (Clark \& Sengul, I978), taking the listener's perspective and adjusting a linguistic form accordingly in the flow of conversation seems to be an ability that develops after preschool years (Pan \& Snow, r 999).

Thus, our findings are actually not as surprising as research on early joint attention would suggest in the first flush. What we are examining is a qualitatively distinct conversational attention behavior than what is observed in late infancy and toddlerhood-an ability more reliant on the monitoring and manipulating of attention state of interactants in conversation.

However, another reason for Turkish children's demonstrative use patterns could be related to the input. That is, $b u$ might be more frequent than şu in child-directed speech, leaving children with inadequate opportunities to figure out the subtleties of the usage of şu. This claim seems to be partially correct in our ongoing work about mother-child interactions collected during the same lego task used in this study: we found mothers to be using şu much less frequently when they talk to their children compared to the patterns found in adult-adult conversations. Relative infrequency in the use of this demonstrative compared to the other DPs in child-directed speech might be partially responsible for why it takes longer to acquire its functions.

Our findings also show that adultlike competence in encoding attentional contrasts not only develops late but also in bits and pieces. We have found that six-year-olds show better sensitivity to the eyegaze status of the addressee when using şu than four-year olds, even though six-year-olds still do not show the adultlike patterns. Given that six-year-olds carry out 'theory-of-mind' tasks better than four-year-olds (e.g. Wellman, Cross \& Watson, 200I), we can claim that the six-year-old group has more cognitive competence in terms of monitoring other people's mental states, such as where their current attentions are focused on. 
It should be underlined that one of the strengths of this work, aside from being the first study on Turkish children's acquisition of DPs, lies in its method of looking at conversational settings in assessing the use of DPs along with spatial features of the context. However, further research that examines the use of DPs in activity types or contexts of use other than goal-directed collaborative task is necessary. In addition, our findings are specific to the production of DPs rather than their comprehension. A more comprehensive account of pragmatic development regarding Turkish DPs should take into consideration their comprehension at different ages. Finally, in this first empirical study on the use of Turkish demonstratives, we focused on the use of $s ̧ u$ as encoding contrasts in addressee's visual attention as proposed in Özyürek (1998) and Özyürek \& Kita (2000). Further research is necessary to find out how encoding general cognitive attention in, for example, endophoric uses of demonstratives (e.g. manipulation of given/old information in discourse, anaphoric, cataphoric uses etc.), might interact with that of visual attention in adult and child use of demonstratives in Turkish and in other languages.

In sum, deliberate manipulation of someone else's attention and the highlighting of a certain aspect of the speaker's perception via language is a sophisticated feat of human communication. This ability includes recipient-designed reference (Hindmarsh \& Heath, 2000) that involves collaborative achievement of mutual orientation to objects and places. The language specific development of the use of Turkish demonstratives in preschool children demonstrates that designing their referential forms in consideration of their recipient's attentional status is a pragmatic feat that takes more than six years to develop. In further research, we need to detect when and through what mechanisms this pragmatic ability takes adultlike character.

\section{REFERENCES}

Anderson, S. \& Keenan, L. E. (1985). Deixis. In T. Shopen (ed.), Language typology and syntactic description: grammatical categories and the lexicon, Vol. 3. Cambridge: CUP.

Bates, E., Camaioni, L. \& Volterra, V. (I975). The acquisition of performatives prior to speech. Merrill-Palmer Quarterly 21, 205-26.

Bavin, E. L. (1987). Anaphora in children's Warlpiri. Australian Review of Applied Linguistics Iо, I-I I.

Berman, R. A. \& Slobin, D. I. (1994). Relating events in narrative: a crosslinguistic developmental study. Hillsdale, $\mathrm{NJ}$ : Erlbaum.

Burenhult, N. (2003). Attention, accessibility, and the addressee: the case of Jahai demonstrative ton. Pragmatics 13, $36_{3}-79$.

Capirci, O., Iverson, J., Pizzuto, E. \& Volterra, V. (1996). Gestures and words during the transition to two-word speech. Fournal of Child Language 23, 645-73.

Clancy, P. (1992). Referential strategies in the narratives of Japanese children. Discourse Processes 15, 44I-67.

Clark, E. V. (2003). First language acquisition. Cambridge: CUP. 
Clark, E. \& Sengul, C. J. (1978). Strategies in the acquisition of deixis. Fournal of Child Language 5, 457-75.

Dasinger, L. (I995). The development of discourse competence in native Finnish speaking children: a study of the expression of definiteness. Unpublished doctoral dissertation, University of California, Berkeley.

Fillmore, C. (1997). Lectures on deixis. Stanford, CA: Center for the Study of Language and Information.

Hallan, N. (200I). Paths to prepositions? A corpus-based study of the acquisition of a lexicogrammatical category. In J. Bybee \& P. Hopper (eds), Frequency and the emergence of linguistic structure. Amsterdam/Philadelphia: John Benjamins Publishing Company.

Hanks, W. F. (1990). Referential practise: language and lived space among the Maya. Chicago: Chicago University Press.

Hickmann, M., Hendriks, H., Roland, F. \& Liang, J. (I996). The marking of new information in children's narratives: a comparison of English, French, German, and Mandarin Chinese. Fournal of Child Language 3, 591-610.

Hindmarsh, J. \& Heath, C. (2000). Embodied reference: a study of deixis in workplace interaction. Fournal of Pragmatics 32, $1855-78$.

Karmiloff-Smith, A. (1979). A functional approach to language: a study of determiners and reference. Cambridge: CUP.

Kemmerer, D. (I 999). Near and far in language and perception. Cognition 73, 35-63.

Kornfilt, J. (I997). Turkish. London: Routledge.

Küntay, A. C. (2002). Development of the expression of indefiniteness: presenting new referents in Turkish picture-series stories. Discourse Processes 33, 77-го .

Lyons, J. (1977). Semantics, volumes I \& 2. Cambridge: CUP.

Nakamura, K. (r 993). Referential structure in Japanese children's narratives: the acquisition of $w a$ and ga. In S. Choi (ed.), Fapanese/Korean linguistics. Stanford: Stanford University Center for the Study of Language and Information.

Özyürek, A. (1998). An analysis of the basic meaning of Turkish demonstratives in faceto-face conversational interaction. In S. Santi, I. Guaitella, C. Cave \& G. Konopczynski (eds), Oralite et Gestualite : Communication multimodale, interaction. Paris : L'Harmattan.

Özyürek, A. \& Kita, S. (2000). Attention manipulation in the situational use of Turkish and Fapanese demonstratives. Paper presented at the Linguistic Society of America Conference, Chicago.

Pan, B. A. \& Snow, C. E. (r 999). The development of conversational and discourse skills. In M. Barrett (ed.), The development of language. Hove, UK: Psychology Press.

Rodrigo, M. J., Gonzalez, A., de Vega, M., Muneton-Ayala, M. \& Rodriguez, G. (2004). From gestural to verbal deixis: a longitudinal study with Spanish infants and toddlers. First Language 24, 7 I-90.

Tanz, C. (1980). Studies in the acquisition of deictic terms. Cambridge: CUP.

Tomasello, M. \& Haberl, K. (2003). Understanding attention: I2- and I 8-month-olds know what is new for other persons. Developmental Psychology 39, 906-12.

Underhill, R. (1976). Turkish grammar. Cambridge: MIT Press.

Wales, R. (I 986). Deixis. In P. Fletcher \& M. Garman (eds), Language acquisition: studies in first language development. Cambridge: CUP.

Wellman, H. M., Cross, D. \& Watson, J. (200I). Meta-analysis of theory-of-mind development: the truth about false belief. Child Development 72(3), 655-84.

Wigglesworth, G. (I990). Children's narrative acquisition: a study of some aspects of reference and anaphora. First Language ro, 105-25. 